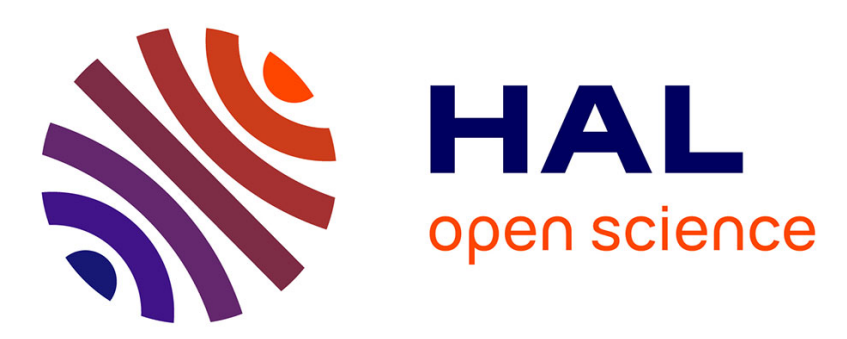

\title{
SCALING LAW VARIATION OF THE MECHANICAL PROPERTIES OF SILICA AEROGELS
}

\author{
T. Woignier, J. Phalippou
}

\section{To cite this version:}

T. Woignier, J. Phalippou. SCALING LAW VARIATION OF THE MECHANICAL PROPERTIES OF SILICA AEROGELS. Journal de Physique Colloques, 1989, 50 (C4), pp.C4-179-C4-184. 10.1051/jphyscol:1989429 . jpa-00229505

\section{HAL Id: jpa-00229505 https://hal.science/jpa-00229505}

Submitted on 1 Jan 1989

HAL is a multi-disciplinary open access archive for the deposit and dissemination of scientific research documents, whether they are published or not. The documents may come from teaching and research institutions in France or abroad, or from public or private research centers.
L'archive ouverte pluridisciplinaire HAL, est destinée au dépôt et à la diffusion de documents scientifiques de niveau recherche, publiés ou non, émanant des établissements d'enseignement et de recherche français ou étrangers, des laboratoires publics ou privés. 
REVUE DE PHYSIQUE APPLIQUEE

Colloque C4, Supplément au $\mathrm{n}^{\circ} 4$, Tome 24, avril 1989

\title{
SCALING LAW VARIATION OF THE MECHANICAL PROPERTIES OF SILICA AEROGELS
}

\author{
T. WOIGNIER and J. PHALIPPOU \\ Laboratoire de Science des Matériaux vitreux, Université des Sciences \\ et Techniques du Languedoc, F-34060 Montpellier Cedex 2, France
}

\begin{abstract}
Résumé - Le comportement mécanique des aérogels de silice est étudié par la méthode de flexion 3 points. Le module d'Young $(E)$, la résistance à la rupture (S) et la ténacité (KIC) sont étudiés en fonction des paramètres de préparation. Il est démontré que l'évolution des caractéristiques mécaniques suit une loi d'échelle en fonction de la densité. Les résultats expérimentaux sont examinés sur la base de la théorie de la percolation.
\end{abstract}

Abstract - The mechanical behaviour of silica aerogels is studied by the three points flexural technique. The Young's modulus (E), the fracture strength (S) and the toughness KIC are investigated as a function of the different preparation parameters. It is demonstrated that the evolution of mechanical characteristics as a function of the apparent density follows scaling laws. The evaluated exponents are $3.7,2.6$ and 1.6 for $E, S$ and KIC respectively. The experimental data are discussed in terms of the percolation theory.

\section{1 - INTRODUCTION}

The utilization of glasses and ceramics in structural applications is often hampered by the inherent brittle nature of these materials which results in a substantial variability in the mechanical properties. That is particularly thrue for aerogels, which are porous ceramics where the solid part represents between 1 to $30 \%$ of the whole volume.

Due to their uncommon physical properties (very low thermal conductivity, high specific surface area, low refractive index) silica aerogels have a .. large potential as transparent thermal insulator, Cerenkow radiator and catalyzing support. Recently, silica aerogels have been used as precursors for the synthesis of pure silica glass /1/. However, little is known regarding the mechanical properties of such materials.

Moreover a new interest is actually devoted to aerogels because of their fractal nature. They offer thus, the possibility to experimentally study the mechanical properties of real fractal objects.

Preliminary studies on aerogels reported the measurements of the elastic constants by Brillouin scattering $/ 2 /$ and ultrasonic measurements $/ 3,4 /$. In this work we present a more detailed study of the mechanical properties measured by the three-points flexura] technique. This technique gives informations on the elastic behaviour (Young's modulus) but also on the fracture features such as strength and toughness.

This static manner to determine the Young's modulus gives complementary information to the high frequency measurements. The experiments have been performed on different sets of samples in order to investigate the influence of the preparation conditions ( $\mathrm{pH}$, dilution) on the mechanical properties.

Recently, it has been suggested that there is an analogy between gelation and percolation which is a critical process for connectivity. This analogy was supported by experimental studies giving results in agreement with model predictions. In this work we will discuss our experimental results in terms of this analogy.

\section{2 - EXPERIMENTAL}

The gels are elaborated by hydrolysis and polycondensation reactions of tetramethoxysilane (T.M.O.S). The T.M.O.S. was dissolved in various amounts of methanol thereby adjusting the final bulk density. The solutions are hydrolyzed under neutral, basic $\left(5.10^{-2} \mathrm{~N} \mathrm{NH}{ }_{4} \mathrm{OH}\right)$ or acidic $\left(10^{-4} \mathrm{~N} \mathrm{HNO}_{3}\right)$ conditions. The number of water molecules is four times that of TMOS. The gels are allowed to cure at $55^{\circ} \mathrm{C}$ for two weeks. The alcogels are transformed into aerogels by hypercritical evacuation of the methanol.

The apparent density is determined by simply weighing the samples of well defined 
dimensions. The pore volume is calculated from apparent and skeletal densities, the 1atter being close to 1.85 for neutral or acidic aerogels, 2 for basic aerogels $/ 5 /$.

The Young's modulus $E$ and mechanical strengh $S$ were measured by a standard three points flexural method. The bar-shaped were supported on edges and the load was applied in the center. $E$ and $S$ are then given by :

$$
\begin{aligned}
& E=\frac{d^{3} F}{4 e^{3} 1 \cdot w} \\
& S=\frac{3 F d}{2 e^{2} 1}
\end{aligned}
$$$$
-1-
$$

$F$ is the applied load, $e$ and 1 are the thickness and the width of the sample, d is its length and $w$ is the deformation produced by $F$. The given experimental values represent the average of at least three measurements.

The critical stress intensity factor or fracture toughness (KIC) was measured using the single edge notched beam technique (S.E.N.B) in three points bending.

$$
K_{\text {IC }}=\frac{3 F d}{2 e^{2} 1} \sqrt{c} y
$$

where $c$ is the notch depth cut with a diamond saw, $Y$ is a polynomial expression which depends on the geometry of the test. (For details see reference 6).

The presented results were obtained on aerogels prepared with at 1 east $10 \%$ of tetramethoxysilane. Aerogels having TMOS volumic concentrations lower than $10 \%$ can be prepared. As an example we have synthesized alcogels with $1 \%$ of TMOS. They give rise to aerogels containing $99 \%$ of porosity. However, attemps to measure the mechanical properties of such "materials" have failed.

\section{3 - RESULTS AND DISCUSSIONS}

For all the studied aerogels the mechanical behaviour is characteristic of a brittle perfectly elastic materiaj. The surface aspect of the fracture is identical to that of a glass.

Figure 1 shows the evolution of the Young's modulus $E$ and the mechanical strength $S$ of silica aerogels as a function of the initial TMOS concentration under acidic (A), neutral $(N)$ and basic (B) hydrolysis conditions. $E$ and $S$ cover a broad range of values (4 and 3 orders of magnitude) and thus the experimental data are plotted on a semi-log scale. The observed dispersion in the strength values of aerogels is due to the scatter in the size and shape of the flaws.

$E$ and $S$ decrease with increasing dilution and rising $p H$ of the catalysis. This behaviour is directly related to the decrease of the bulk density. A high dilution leads to a more porous material. At a given dilution, the denser structure of the serie $A$ and $N$ is due to a strong shrinkage occuring during the aging and the autoclave treatment (figure 2). To compare the different series of samples, the results has been plotted versus the buik density (figure 3 ).

The plot on a log-log scale demonstrates the power law dependence of $E$ and $S$.

$$
\begin{array}{lr}
E \propto \rho^{3.7} \pm 0.2 & -4- \\
S \propto \rho^{2.6} \pm 0.2 & -5
\end{array}
$$

Regarding the elastic behavior of this material differents comments can be given.

The same scaling exponent has been found for the high frequency determination of the elastic constant in the Mhz and Ghz range, demonstrating that the samples exhibit a large scale homogeneity. $\mathrm{C} 11$ et $\mathrm{C} 44$ elastic constants /2/ have also shown to obey the same power dependence which leads to the conclusion that the ratio of the compressibility $K$ to the shear modulus $G$ and the poisson's ratio $\mu$ remain about constant in the studied density range. The calculated values $K / G=1.4$ and $\mu=0.2$ are very close to that of dense vitreous silica.

The three series of samples exhibit the same scaling law dependence. However for a given bulk density base catalyzed series shows $E$ values slightly lower. This result has been explained by a smaller connectivity of the $B$ network compared to that of the $A$ and $N$ materials /7/. Strength does not show the same behaviour with respect to data scattering and the fact that $S$ is governed by connectivity but is also related to the existence of flaws in 


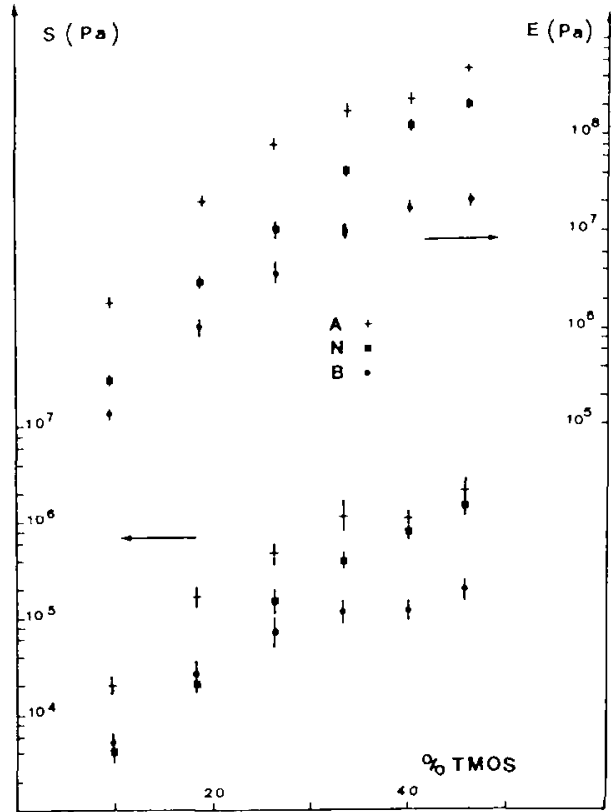

Fig. 1 - Evolution of mechanical properties of aerogels made under various conditions as a function of TMOS concentration.

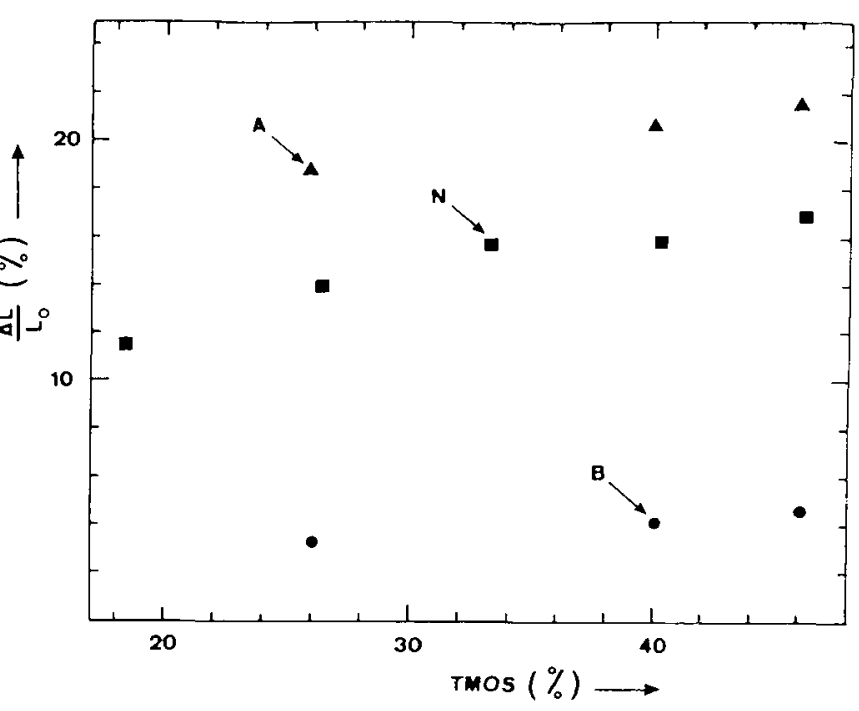

Fig. 2 - Linear shrinkage induced by the gel-aerogel conversion as a function of TMOS concentration.

the material.

The scaling law behaviour observed for the Young modulus can be discussed in terms of percolation theory. This theory treats the occupation of random sites by entities on a fixed lattice leading to the appearance of a coherent network at the percolation threshold /8/. In this theory, the elastic constants are expected to scale as :

$$
K \propto G \propto E \propto\left(p-p_{c}\right)^{\tau}-6-
$$

where $p$ is the probability for sites to be occupied, $p_{c}$ the percolation threshold is defined as the value of $p$ above which an infinite cluster exists.

It has been proposed / 3 / that for silica aerogels a good approximation is to identify $p$ with $\rho$ and to let $\rho_{c} \simeq 0$. With such an assumption we find that $\tau=3.7 \pm 0.2$ which is in an excellent agreement with the theoretical percolation predictions [9, 10]. Moreover the fact that the scaling relation equally applies to the compressibility, shear and Young moduli is also in agreement with the percolation predictions.

Let us see what the percolation model proposes for the mechanical strength. While the behavior of the elastic moduli of percolating object has been the focus of a number of theoretical investigations, on the other hand very little attention has been paid to the fracture properties of tenuous solids. First investigations have been performed on a two dimensional model $/ 11,12 /$. Thus also a power 7 aw dependence of the strength is predicted.

$$
s \alpha\left(p-p_{c}\right)^{t} \quad-7-
$$

However the value of the scaling exponent and the interpretation of the results differ $/ 11,12,13,14 /$. $15 /$.

Recently Ray and Chakrabarti have proposed a lower bound for the scaling exponent $t$

$$
t \geq 1 / 2(\tau+(D-D B) \nu)
$$

where $\tau$ is the elasticity exponent, $D$ the dimensionality, DB the fractal dimension of the percolative blackbone (the set of sites which carry the stress) and $v$ the correlation length exponent. The derivation is made under the explicit assumption that the system is microscopically brittle. That is verified in our case. Inserting the value $\tau=3.7 / 9,10 /, 0=3$, $D_{8}=2 / 16 /$ and $\nu=0.8 / 8 /$ we find that $t \geq 2.25$. Proceeding with the same approximation 
than above $/ 3 /$, our experimental results $t=2.6$ would be in a good agreement with the theoretical lower bound.

ATI these results and comments would suggest that the aerogel is a percolative medium. This conclusion is not so clear after a second analysis.

First of all, the critical behaviour in the percolation theory is defined "near" the percolation threshold. The ligthest aerogel which has been obtained has a volume fraction of solid around $1 \%$ which would correspond to the percolation threshold. Then the studied aerogels having a fraction of solid between 5 to $30 \%$ cannot be regarded as materials close to the threshold point.

The comparison between the experimental determinations and the percolation predictions of the exponent values are based on the assumption that the unknown mathematical variable $p-p_{c}$ can be replaced directly by $\rho$. The hypothesis assumes implicitly that all the occupied sites (monomers having reacted) belong to the infinite cluster (gel network). In fact, in the gelation-percolation analogy $/ 8 \%$, the bulk density (or gel fraction) is correlated to the percolation probability (which is defined as the probability for a site to belong to the infinite cluster) and scales with the $\beta$ exponent.

$$
\rho \propto P(p) \propto\left(p-p_{c}\right)^{\beta} \quad-9 \text { - }
$$

The relation takes into account the fact that a part of the occupied sites do not participate to the infinite cluster. With the relations 6,7 and 9 , the following scaling relations can be derived.

$$
\begin{array}{lr}
E \propto \rho^{T / \beta} & -10- \\
S \propto \rho^{t / \beta} & -11-
\end{array}
$$

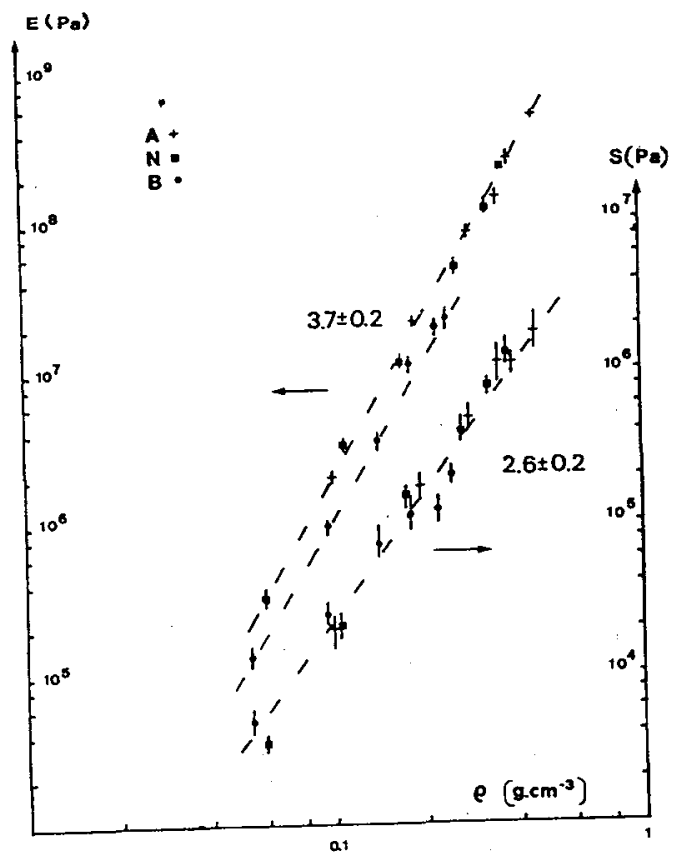

Fig. 3 - Evolution of mechanical properties of aerogels as a function of their density.

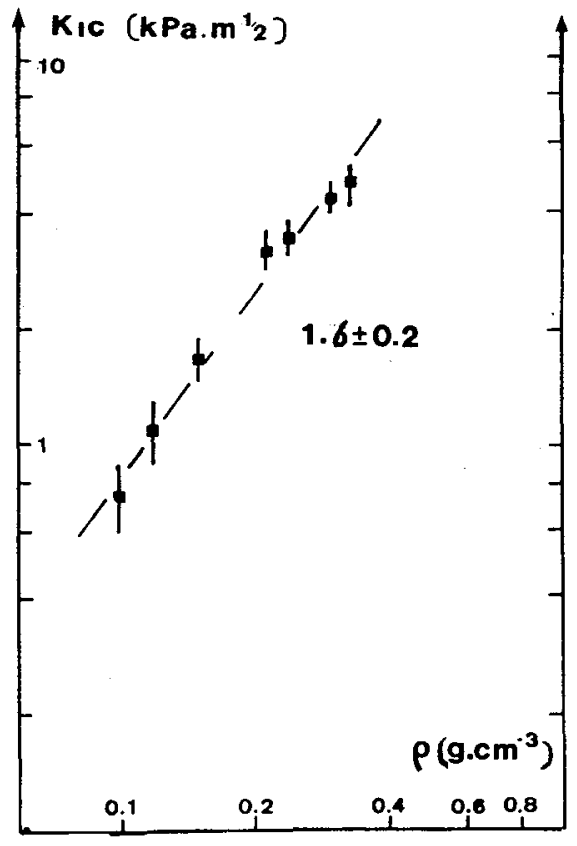

Fig. 4 - Fracture toughness vs density.

and the experimentally determined values are not directly $\tau$ or $t$ but $\tau / \beta$ or $t / \beta$. Some authors have used for polyurethane gels $/ 17 /$ and for silica gels / $/ 18 /$ a $\beta$ value close to 0.4 . This value corresponds to the theoretical prediction in a 3 dimensional static lattice $18 /$.

We can conclude that $\tau \simeq 1.5$ and $t \simeq 1.1$ which are far from the percolation exponents. However in the case of the formation of silica alcogel and during the autoclave treatment aging and syneresis phenomena allow microclusters to stick to the infinite cluster. In this way the growth of the gel can be regarded as a $3 D+1$ dimension problem, 3 space and one time dimensions. The addition of the microclusters induce an increase of the 
gel density and one expects a larger value of $\beta$. Recent work $/ 19 /$ proposes a $\beta$ value equal to 0.83 in $3 D+1$ dimensions, which would lead to $\tau \simeq 3.1$ and $t \simeq 2.2$.

The comments we have developed above show that different interpretations issued from the literature lead to contradictary conclusions. For silira aerogels the existence of scaling laws and the experimental determination of exponents are not thought to be sufficient criteria to check if these materials can be compared to percolative network.

The analysis in terms of percolation theory can be also discussed considering the structure of the aerogel and the comparison between the fractal dimensions $D_{f}$. Thus, the fractal dimension of the percolation infinite cluster is 2.5 al though the fractal dimension of the aerogels is around 1.8 in basic catalysis and 2.4 for the $A$ and $N$ sets $/ 20 \%$. Such values of $\mathrm{Df}$ would suggest that the growth process in basic catalysis corresponds to a cluster-cluster aggregation limited by diffusion $(D=1.8 / 21 /)$. For the $A$ and $N$ series, a cluster-cluster aggregation limited by reaction $(D=2.1 / 21 /)$ followed by rearrange-ment of the clusters during the syneresis phenomenon (which leads to a denser structure) can explain the value $D \approx 2.4$.

The fact that the gelation under basic conditions is very fast (1ike D.L.C.A.) and slower under neutral and acidic catalysis (like R.L.C.A.) is supporting these ideas.

It is noteworthy that basic, neutral, acidic sets of aerogels exhibit the same scaling exponents. These exponents seem to be independent on the aggregation process and thus the aeroge 7 structure. Thus, an identification of the aerogei structure with the infinite cluster of percolation can only be an approximation.

Preliminary experiments have been performed to obtain the toughness of these brittle materials. The measurements have been done on the $N$ set. The experimental results are discussed in more details in a companion paper $/ 6 /$. KIC exhibits aiso a power law dependence with $\rho$ (fig. 4).

$$
\text { KIc } \propto \rho^{1.6 \pm 0.2}
$$

The toughness characterizes the property of materials to resist the crack propagation. Strength of ceramics $S$ is related to KIC and to the size of the fracture initiating flaw.

$$
S=\frac{Z}{y} \frac{K_{I C}}{\sqrt{\ell}}
$$

$\ell$ is the critical size of the $f l$ aw responsible for the failure, $Y$ is a geometrical parameter close to $2 / 23 /$ and $Z$ is known as a flaw shape parameter $/ 24 /$ (for an ideal Griffith flaw $Z=1$ and relation 14 is equivalent to the relation 3 of the SENB test).

If we assume that $Z=1 \ell$ would vary between 10 and $100 \mu m$ which is close to the Griffith flaw found in dense silica glass. However the nature of the flaws is not well identified, flaws may be microcracks passing through several particles and micropores. Another possibility is to consider that pores are responsible for the failure either, because they concentrate stress on flaws away from the pore, either because they are themselves considered as a 3 dimensional not sharp flaws. In this approach fracture is regarded as originating from the biggest pores $/ 25 \%$.

\section{4 - CONCLUSION}

A very large variation of the mechanical properties of silica aerogels is observed over the density range $0.05-0.4 \mathrm{~g} / \mathrm{cm}^{3}$. Elastic moduli, mechanical strength and toughness scale with exponents equals to $3.7,2.6$ and 1.6 respectively.

It has been proposed that the gelation can be described by a percolation process in which the exponents are related to different classes of universality. However in the case of silica aerogel, the interpretation in terms of percolative network seems questionable. First of all the choice of the physical parameters which are used to account for the unknown

mathematical variable $p-p_{c}$ is not obvious. On a structural point of view, the fractal structure of the aerogels is different of the infinite cluster of the percolation theory and depends on the catalysis conditions. Finally, the aerogel network is the result of a sequence of different processes such as gelation, aging and syneresis shrinkage. Interpretation of the whole phenomenon by a unique model would be daring.

\section{REFERENCES}

/1/ PHALIPPOU, J., WOIGNIER, T., PRASSAS, M., same issue 
12/ COURTENS, E., PElous, J., PHAlipPOU, J., VACHER, R., WOIGNier, T., Phys. Rev. Lett., $\underline{58}$ (1987) 128.

/3/ GRONAUER, M., KADUR, A., FRICKE, J., Aerogels (Springer Verlag) (1986) Proceeding in Physics. 6-167.

14/ CALEMCZUK, R., DE GOER, A.M., SALCE, B., MAYNARD, R., ZAREMBOVITCH, A., Europhysic Letters, $\underline{3}$ (1987) 1205 .

/5/ WOIGNIER, T., PHALIPPOU, J., J. Non-Cryst. Solids, $\underline{93}$ (1987) 17.

16/ PHALIPPOU, J., WOIGNIER, T., RQGIER, R., same issue.

17) WOIGnier, T., PHALIPPOU, J., VACHER, R., Spring Meeting M.R.S., Reno, (1988) to be published.

18/ STAUfFER, D., J. Chem. Soc. Faraday Trans., 72 (1972) 1354.

19/ FENG, S., SEN, R.N., Phys. Rev. Letters, $\underline{52}$ (1984) 216.

/10/ KanTOR, Y., WEBMAN, I., Phys. Rev. Letters, $\underline{52}$ (1984) 1891.

/11/ SIERADZKI, K., LI, R., Phys. Rev. Letters, $\underline{56}$ (1986) 2509.

/12/ BENGUIGUI, L., RON, P., BERGMAN, D.J., preprint.

/13/ RAY, P., CHAKRABARTI, B.K., J. Phys. C : Solid State Phys., 18 (1985) L 185.

/14/ SORNETTE, D., Physical Review B, $\underline{36}$ (1987) 8847.

/15/ RAY, P., CHAKRABARTI, B.K., preprint.

/16/ KIRKPATRICH, S., in III Condensed Mater, BALLINA, R., MAYNARD, R., TOULOUSE, G., eds, North-Holl and (1979).

/17/ ADAM, M., DELSANTI, M., MUNCH, J.P., DURAND, D., J. Phys., 48 (1987) 1809.

/18/ DEUTSCHER, G., MAYNARD, R., PARODI, 0., Europhysics Letters, $\underline{6}$ (1) (1988) 49.

/19/ ADLER, J., BERGER, J., DUARTE, J.A.M.S., MEIER, Y., Phys. Rev. B, $\underline{37}$ (13) (1988) 7529.

/20/ VACHER, R., WOIGNier, T., PELous, J., COURTENS, E., Phys. Rev. B, $\underline{37}(11)$ (1988) 6500 .

/21/ KOLB, M., BOTET, R., JULIEN, J., Phys. Rev. Lett., $\underline{51}$ (1983) 1123.

/22/ SCHAEFER, D.W., "Physics and Chemistry of Porous Media II", Ridgefield (1986) 63.

123/ BROWN, W.F., SRAWLEY, J.E., Am. Soc. Mater., Spec. Tech. Publ., 410 (1967) 1.

124/ EVAnS, A.G., TAPPIN, G., Proc. Br. Ceram. Soc. 1972, 20 (1972) 275.

125/ RICE, R.W., "Treatise on materials science and technology", Vol. II, R.K. Mac Crone ed., Acad. Press, (1977) 199. 